\title{
Scube/You activity mediates release of dually lipid-modified Hedgehog signal in soluble form
}

\author{
Adrian Creanga, ${ }^{1,2,3}$ Thomas D. Glenn, ${ }^{2}$ Randall K. Mann, ${ }^{1,2,4}$ Adam M. Saunders, ${ }^{1,2,4}$ \\ William S. Talbot, ${ }^{2}$ and Philip A. Beachy ${ }^{1,2,3,4,5}$ \\ ${ }^{1}$ Institute for Stem Cell Biology and Regenerative Medicine, ${ }^{2}$ Department of Developmental Biology, Stanford University, \\ Stanford, California 94305, USA; ${ }^{3}$ Department of Molecular Biology and Genetics, The Johns Hopkins Medical Institutions, \\ Baltimore, Maryland 21205, USA; ${ }^{4}$ Department of Biochemistry, Stanford University, Stanford, California 94305, USA
}

Owing to their covalent modification by cholesterol and palmitate, Hedgehog (Hh) signaling proteins are localized predominantly to the plasma membrane of expressing cells. Yet Hh proteins are also capable of mobilizing to and eliciting direct responses from distant cells. The zebrafish you gene, identified genetically $>15$ years ago, was more recently shown to encode a secreted glycoprotein that acts cell-nonautonomously in the Hh signaling pathway by an unknown mechanism. We investigated the function of the protein encoded by murine Scube2, an ortholog of you, and found that it mediates release in soluble form of the mature, cholesterol- and palmitate-modified Sonic hedgehog protein signal ( $\mathrm{ShhNp}$ ) when added to cultured cells or purified detergent-resistant membrane microdomains containing ShhNp. The efficiency of Scube2-mediated release of ShhNp is enhanced by the palmitate adduct of ShhNp and by coexpression in ShhNp-producing cells of mDispatchedA (mDispA), a transporter-like protein with a previously defined role in the release of lipid-modified Hh signals. The structural determinants of Scube2 required for its activity in cultured cell assays match those required for rescue of you mutant zebrafish embryos, and we thus conclude that the role of Scube/You proteins in Hh signaling in vivo is to facilitate the release and mobilization of $\mathrm{Hh}$ proteins for distant action.

[Keywords: DispatchedA; Hedgehog; Scube2; morphogen release; palmitate]

Supplemental material is available for this article.

Received March 12, 2012; revised version accepted May 9, 2012.

The Hedgehog (Hh) signaling pathway plays critical roles in embryonic growth and patterning in organisms ranging from insects to mammals and also functions postembryonically in tissue homeostasis (Beachy et al. 2004; Varjosalo and Taipale 2008). Furthermore, inappropriate activity of the Hh signaling pathway has been linked to tumor types that arise sporadically or in genetically predisposed individuals (Teglund and Toftgard 2010). Response to the Hh protein signal is mediated by Patched (Ptch), a transporter-like 12-pass transmembrane protein that inhibits the seven-transmembrane protein Smo (Wilson and Chuang 2010). When present, the Hh protein signal binds Ptch and blocks its inhibition of Smo, thus permitting activation of an intracellular signal cascade that results in execution of a transcriptional program mediated

${ }^{5}$ Corresponding author

E-mail pbeachy@stanford.edu

Article published online ahead of print. Article and publication date are online at http://www.genesdev.org/cgi/doi/10.1101/gad.191866.112. Freely available online through the Genes \& Development Open Access Option. by the $\mathrm{Ci} / \mathrm{Gli}$ family of latent cytoplasmic transcription factors (Varjosalo and Taipale 2008).

The Hh protein signal heading this pathway is produced as a precursor that undergoes cleavage and cholesterol modification in an autoprocessing reaction, and the cholesterol-modified $\mathrm{N}$-terminal signaling domain is further modified by covalent addition of palmitate, mediated by an acyltransferase (Mann and Beachy 2004; Buglino and Resh 2008). These lipid modifications are particularly well characterized for Drosophila $\mathrm{Hh}$ (Hh N-terminal processed domain [HhNp]) and the mammalian Hedgehog family member Sonic hedgehog (ShhNp), but likely are conserved for all or most Hh family members (Mann and Beachy 2004). The lipid adducts cause the mature Hh signal to associate prominently with the plasma membrane of expressing cells, yet the Hh signal can elicit direct responses at considerable distances from the cells in which it is produced. Thus, for example, Hh proteins can elicit direct responses five to 10 cell diameters from their site of production in the Drosophila wing imaginal disc ( $\sim 50 \mu \mathrm{m}$ in wing imaginal disc) (Strigini and Cohen 1997; Zhu and Scott 2004; Eugster et al. 2007) and at sig- 
nificant distances from their sources within the developing limb bud ( $200 \mu \mathrm{m}$ in limb bud) (Wang et al. 2000; Li et al. 2006) or neural tube ( $\sim 50 \mu \mathrm{m}$ in neural tube) (Briscoe et al. 2001; Chamberlain et al. 2008).

One factor involved in Hh release is the transporterlike protein Dispatched (Disp), related to Patched in sequence and predicted transmembrane topology. In the absence of Disp activity, $\mathrm{HhNp}$ is not released and accumulates in Hh-producing cells (Burke et al. 1999). Loss of Disp function in vertebrates also disrupts the release of processed Hh proteins and produces a severe phenotype equivalent to the loss of multiple Hh family members (Caspary et al. 2002; Kawakami et al. 2002; Ma et al. 2002; Nakano et al. 2004). Interestingly, a Hh $\mathrm{N}$-terminal domain lacking cholesterol, which can be generated by expression of a truncated form of the Hh open reading frame, can spread further from the site of biogenesis and elicit ectopic Hh pathway activation (Porter et al. 1996a,b; Li et al. 2006), thus eliminating the requirement for disp function (Burke et al. 1999). Disp activity thus overcomes the restriction of $\mathrm{HhN}$ release that is imposed by cholesterol modification (Porter et al. 1996a,b; Li et al. 2006). Palmitoylation of the Shh protein signal, on the other hand, appears to promote its mobilization, as loss of palmitoylation diminishes the range of Shh protein distribution through an as yet uncharacterized mechanism (Chen et al. 2004; Chamberlain et al. 2008).

We investigate here the Hh pathway function of vertebrate Scube (signal sequence, cubulin domain, epidermal growth factor-related) proteins, which contain nine EGF repeats and one CUB domain that are linked by a highly glycosylated spacer region (Grimmond et al. 2000, 2001; Yang et al. 2002; Wu et al. 2004). While initially isolated and characterized in mammals, a functional role for these genes in development was suggested by the finding that the you mutation in zebrafish disrupts the Scube2 gene (Kawakami et al. 2005; Woods and Talbot 2005; Hollway et al. 2006). Zebrafish "you class" developmental mutants are grouped together based on the abnormal U-shaped morphology of the somites and, in general, affect zebrafish orthologs of mammalian Hh pathway components such as Sonic hedgehog (sonic-you), Dispatched (chameleon), Smo (slow muscle-omitted), and Gli2 (you-too) (van Eeden et al. 1996; Schauerte et al. 1998; Karlstrom et al. 1999; Chen et al. 2001; Varga et al. 2001; Nakano et al. 2004). The function in Hedgehog signaling of you, the index mutant of the you class, however, remains elusive.

Clues to the function of the you gene product come from transplantation of marked mutant or wild-type cells into wild-type or mutant hosts. These studies showed that rescuing gene function can be supplied from cells that neither produce nor respond to Hh signals, thus indicating cell-nonautonomy of action (Kawakami et al. 2005; Woods and Talbot 2005). Furthermore, widespread expression of Shh protein by injection of Shh mRNA at the one- to fourcell stage activates $\mathrm{Hh}$ response equivalently in wild-type and you mutant embryos; furthermore, morpholino-based knockdown of $z$ Ptch 1 efficiently activates Hh response in you mutant embryos (Woods and Talbot 2005). These results indicate that $\mathrm{Hh}$ biogenesis and signal transduction machinery are not affected in you mutants (Woods and Talbot 2005) and that the need for you gene function is circumvented by ubiquitous Shh expression. The three members of the murine Scube family in aggregate are expressed in many tissues at many stages of development. Only $m S c u b e 1$, however, has been subjected to mutational analysis, and the associated phenotypes of prenatal lethality, neural tube closure defects, or acrania and exencephaly at birth (Tu et al. 2008) are inconclusive, although potentially consistent with disruption of some aspects of $\mathrm{Hh}$ signaling function.

In the analysis of Scube function presented here, we focused on the Scube2 ortholog of the zebrafish you gene and found an activity in Hh protein release. This activity generates a soluble form of dually lipid-modified ShhNp protein in a manner enhanced by palmitate modification and by the presence of Disp activity. Several portions of the Scube2 protein are dispensable for the release of ShhNp from cultured cells, and a minimal construct with in vitro function in ShhNp release can also rescue you zebrafish mutants, suggesting that Scube proteins function in vivo to release and mobilize Hh proteins for signaling activity.

\section{Results}

Coexpression of Scube2 and Shh increases soluble ShhNp protein levels and signaling activity in cultured cell medium

To examine release of Shh protein signal, we analyzed medium collected from HEK293S cells transfected with a full-length Shh expression construct (Fig. 1A). These cells have previously been used to characterize aspects of Hedgehog protein biogenesis and release (Zeng et al. 2001; Chen et al. 2004). We were unable to detect ShhNp protein by immunoblotting medium incubated with these cells for $1 \mathrm{~d}$, although $2 \mathrm{~d}$ of incubation produced a low but detectable level of ShhNp (Fig. 1B, cf. lanes 1 and 3). The level of ShhNp in the medium increased dramatically upon cotransfection of Shh with Scube2 (Fig. 1B, lanes 2,4).

We also assayed these media for their ability to activate the Hh pathway in Shh-LIGHT2 cells, which contain stably integrated Shh-responsive firefly luciferase and control Renilla luciferase reporters (Fig. 1A; Taipale et al. 2000). We found that expression of Scube2 dramatically enhanced the otherwise low levels of pathway-stimulating activity, particularly with medium conditioned by $2 \mathrm{~d}$ of incubation (Fig. 1B). In contrast, Scube2 expression exclusively in responsive cells did not enhance the Hh-sensitive reporter activity of cells stimulated by ShhN-conditioned medium (Supplemental Fig. 1).

We further characterized the Scube2-enhanced signaling

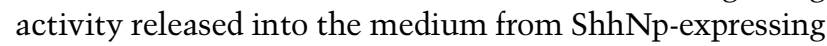
cells by subjecting such medium conditioned for $2 \mathrm{~d}$ to ultracentrifugation at $100,000 \mathrm{~g}$ for $2 \mathrm{~h}$, conditions that would be expected to sediment membrane-associated but not soluble proteins. We found that this affected neither the relative levels of ShhNp protein in the medium (Fig. 
1C, cf. lanes 4,5 and 3,2) nor its signaling activity (Fig. 1C). We thus conclude that Scube2 augments the activity of ShhNp-conditioned medium by increasing the amount of soluble ShhNp and used medium cleared by centrifugation at $100,000 \mathrm{~g}$ for $2 \mathrm{~h}$ throughout the remainder of this work.

\section{Scube2 does not affect ShhNp stability}

To determine whether Scube 2 acts by increasing the stability of secreted ShhNp, we mixed medium containing ShhNp with control medium or medium containing Scube2 protein. These media were harvested following incubation with cells containing stably integrated and doxycyclineinducible expression constructs for Shh or for Scube2 (Fig. 2A). The use of cells with a stably integrated, doxycyclineinducible Shh expression construct allowed us to collect more ShhNp in conditioned medium than with transiently transfected cells (Fig. 1). We found that mixing conditioned medium containing ShhNp with medium containing Scube2 did not increase either the level of ShhNp detected

A.

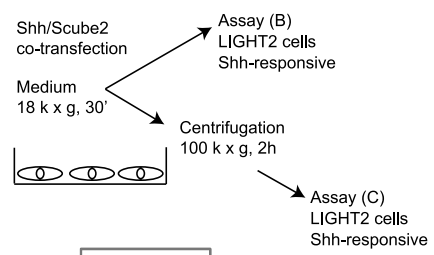

B.

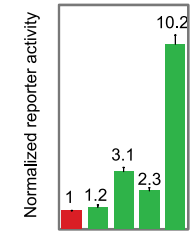
LIGHT2 cells

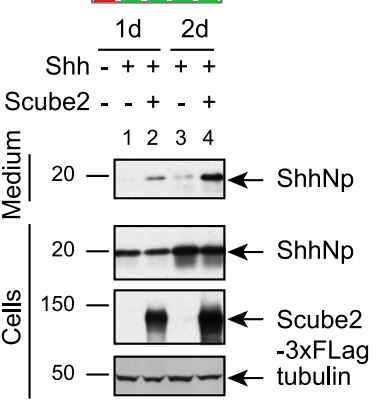

C.

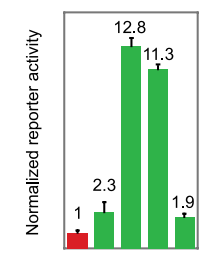

$18 \mathrm{kxg} 100 \mathrm{kxg}$

Shh $\overline{-++} \overline{++}$

Scube2 - - + + -

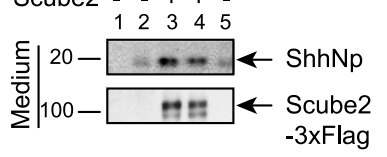

by immunoblotting over time or the signaling activity in Shh-LIGHT2 cells when compared with ShhNp-containing medium mixed with control medium lacking Scube2 (Fig. 2B). Taken together, these observations suggest that Scube2 does not act by stabilizing ShhNp in the medium or by augmenting the potency of ShhNp signaling activity, but by enhancing the release of ShhNp from Shh-expressing cells.

\section{Soluble Scube2 enhances release of ShhNp from Shh-expressing cells}

In our previous experiment (Fig. 1), we noted that coexpression of Scube2 with Shh increased the level of ShhNp protein and of signaling activity released into the medium. Scube 2 has been reported to associate with the membranes of cells expressing it in vitro (Yang et al. 2002), raising the question of whether its function in releasing ShhNp may require presentation in the context of an expressing cell. We tested this possibility by harvesting soluble Scube2 protein in medium incubated with cells that inducibly express Scube2 and then adding this medium to cells inducibly expressing ShhNp (Fig. 2C). We found that addition of exogenous Scube2 greatly enhanced the signaling activity of medium incubated with cells expressing ShhNp and also increased the amount of ShhNp protein detectable in the medium by immunoblotting (Fig. 2D).

Figure 1. Scube2 coexpression with $\mathrm{Shh}$ increases the release of soluble, active ShhNp protein. (A) Medium was harvested from HEK293S cells transiently transfected with expression plasmids for 3xFlag-tagged Scube2 or a control plasmid (see the Materials and Methods) along with Shh (2:1 ratio of Scube2 to $\mathrm{Shh}$ ), and centrifuged at $18,000 \mathrm{~g}$ for $30 \mathrm{~min}$, and signaling was activity measured using Shh-responsive NIH-3T3 cells stably transfected with firefly luciferase-based Shh pathway reporter and Renilla luciferase constitutive reporter (Shh-LIGHT2 cells). Medium harvested $48 \mathrm{~h}$ post-transfection was centrifuged at $100,000 \mathrm{~g}$ for an additional $2 \mathrm{~h}$. (B) Signaling activities of ShhNpconditioned media collected from transfected HEK293S cells at specified time points and incubated for $48 \mathrm{~h}$ with Shh-LIGHT2 cells at a fivefold dilution of conditioned media with DMEM containing $0.5 \%$ calf serum. Relative reporter activities (firefly luciferase/Renilla luciferase) were normalized to relative reporter activity produced by medium collected from HEK293 cells not transfected with the Shh-expressing construct (shown in red here and throughout the study). Culture media and whole-cell lysates harvested from HEK293S cells transiently transfected with the indicated constructs were probed by immunoblotting for expression of ShhNp (anti-ShhN antibody) and 3xFlag-tagged Scube2 (anti-Flag antibody). Tubulin was used as a loading control. Migration of molecular markers is indicated. $(C)$ Scube2 increases the activity of ShhNp-conditioned medium by increasing the amount of soluble ShhNp in the medium. Medium collected $2 \mathrm{~d}$ after transfection and centrifuged at $18,000 \mathrm{~g}$ for $30 \mathrm{~min}$ was further centrifuged at 100,000 for $2 \mathrm{~h}$. The signaling activity of the medium was measured by incubation with Shh-LIGHT2 cells, and protein levels were analyzed by reducing SDS-PAGE and immunoblotting to detect Scube2-3xFlag (anti-Flag) and ShhNp proteins (anti-ShhN). 
A

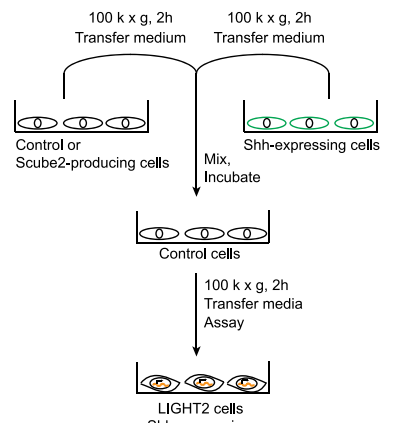

B

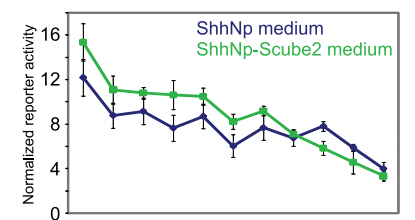

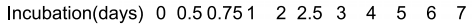

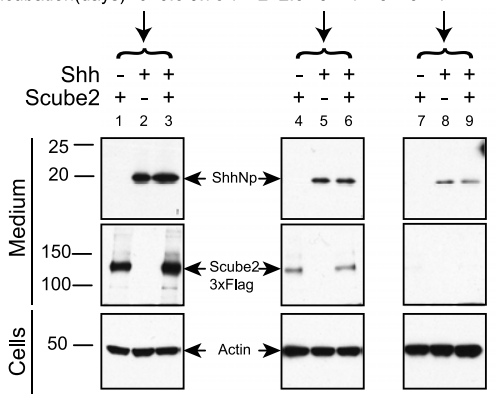

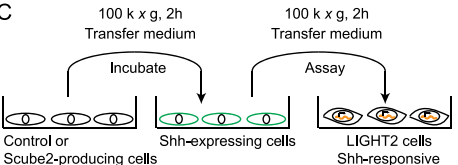

$\mathrm{D}$

$$
\text { . }
$$
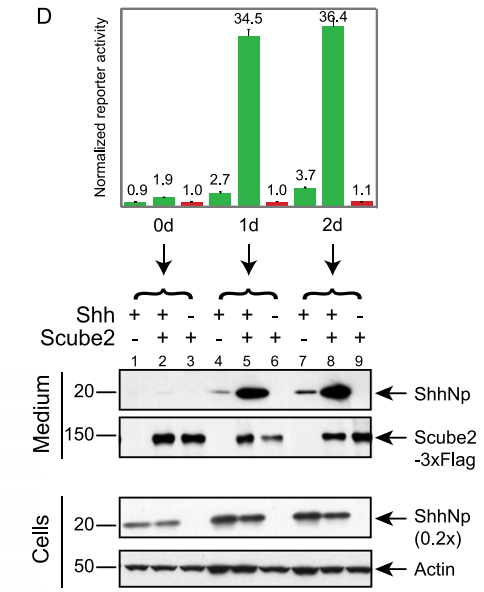

Figure 2. Externally supplied Scube2 acts by enhancing the release of ShhNp. (A) Experimental scheme to test for Scube2-mediated stabilization of ShhNp. HEK293 Flp-In T-REX cells with stably integrated constructs for tetracycline-inducible expression of Shh or 3xFlag-tagged Scube2 were incubated with doxycycline-containing medium. Medium harvested from these or control parental cells was centrifuged at $18,000 \mathrm{~g}$ for $30 \mathrm{~min}$ followed by $100,000 \mathrm{~g}$ for $2 \mathrm{~h}$ and mixed at a $1: 1$ ratio $(\mathrm{v} / \mathrm{v})$ to prepare three distinct conditioned media: (1) Scube2-conditioned medium, with 50\% Scube2conditioned medium and $50 \%$ control conditioned medium from parental cells; (2) ShhNp-conditioned medium, with 50\% ShhNp-conditioned medium and $50 \%$ control conditioned medium; and (3) ShhNp-Scube2-conditioned medium, with 50\% ShhNp-conditioned medium and 50\% Scube2-conditioned medium. Each of these conditioned media was further incubated with parental HEK293 Flp-In cells for the indicated periods of time prior to assay. (B) Scube2 does not affect signaling activity or the stability of secreted ShhNp. Signaling activity of conditioned medium was measured at fivefold dilution with Shh-LIGHT2 cells. Signaling activity of control conditioned medium incubated with cells not expressing Shh was used for normalization. Media samples were also probed for ShhNp (antiShhN) and 3xFlag-tagged Scube2 (anti-Flag) by immunoblotting, with lysates from proportional fractions of cell cultures probed for actin expression as controls. (C) Experimental scheme to test for Scube2-mediated release of ShhNp. Stably integrated, tetracycline-inducible cells were used to prepare control or Scube2-containing medium as described in A. After $12 \mathrm{~h}$ of doxycycline treatment, medium from parental or Shh-expressing cells was replaced with control or Scube2-conditioned medium and incubated for the indicated periods of time. ShhNp-conditioned medium was centrifuged at 18,000g for 30 min, and the resulting supernatant was further centrifuged at 100,000 $\mathrm{g}$ for $2 \mathrm{~h}$. Activity measurements were carried out with Shh-LIGHT2 cells and 20-fold dilution of conditioned media with DMEM containing $0.5 \%$ calf serum. $(D)$ Scube2 stimulates the release of ShhNp protein and signaling activity. Shh-expressing cells were incubated with control or Scube2-containing conditioned medium. Signaling activity of control conditioned medium was used for normalization. Scube2-containing conditioned medium increased signaling activity by $\sim 10$-fold and also increased the release of ShhNp, as detected by immunoblotting (performed as described in $B$ ).

\section{Scube2 surmounts the restriction of ShhNp release imposed by cholesterol modification}

To better understand the mechanism by which Scube2 enhances ShhNp release, we analyzed its effect on altered forms of Shh that are not processed normally. One of these variants, $\mathrm{ShhN}$, introduces a stop codon after the site of processing (G198), thus producing a truncated protein and preventing autoprocessing and the associated cholesterol modification that is mediated by the C-terminal domain (Mann and Beachy 2004). A second variant alters Cys25 to Ser (C25S), thus permitting normal autoprocessing and cholesterol modification while preventing $\mathrm{N}$-terminal palmitoylation (Pepinsky et al. 1998; Chamoun et al. 2001). In an experiment in which Scube2-conditioned medium was added to cells containing stably integrated expression constructs (Fig. 3A), we noted for ShhN that neither signaling activity nor release into the medium is much affected by the addition of Scube2 (Fig. 3B, lanes 1-6). In contrast, the ShhC25S mutant was more efficiently released into the medium in the presence of Scube2 (Fig.
3B, lanes 13-18), although the overall level of protein released was much lower than that of wild-type ShhNp (Fig. 3B, cf. lanes $14,16,18$ and $8,10,12$ ); as previously reported, the ShhNpC25S protein lacks activity in cultured cell signaling assays. Similar results were noted for HEK293 cells transiently cotransfected for coexpression of Shh or ShhC25S with or without Scube2 (Supplemental Fig. 2). These results suggest that Scube2 activity is critical for the release of processed Shh proteins that are cholesterol-modified. We note, however, that palmitoylation may play a role in this release, as wild-type $S h h N p$ appears to be released more efficiently than ShhNpC25S (Fig. 3B).

\section{Palmitate modification of ShhNp enhances Scube2-mediated release}

To explore further the potential role of palmitoylation of ShhNp in Scube2-mediated release, we examined the rate of ShhNp release from cells stably transfected for in- 
A

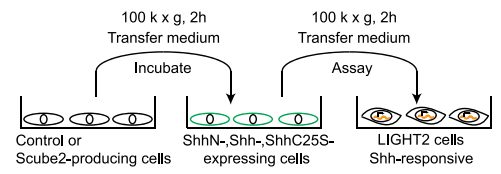

B

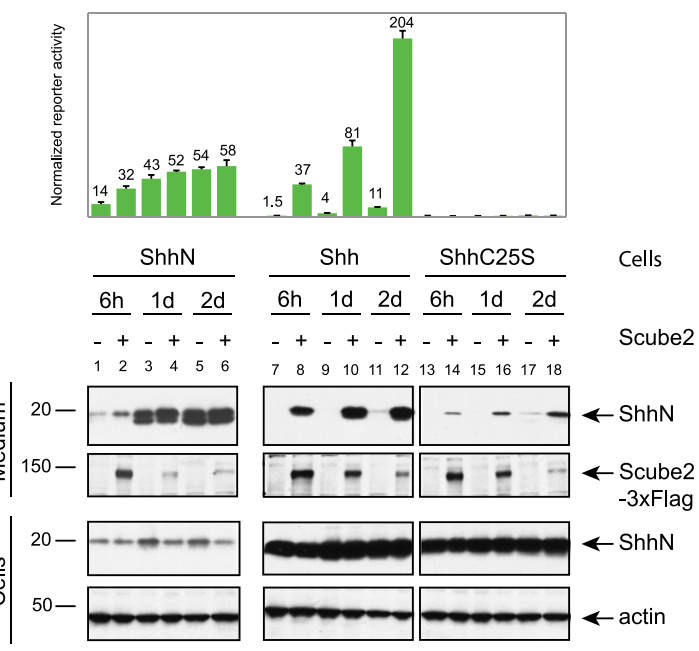

Figure 3. Role of lipid modification in Scube2-mediated release of the Shh signal. (A) HEK293 Flp-In T-REX cells were used to establish isogenic cell lines expressing ShhN, Shh, or ShhC25S. After $24 \mathrm{~h}$ of incubation with doxycycline-containing medium to induce protein expression, cells were incubated with control or Scube2-conditioned medium prepared as in Figure 2C and harvested after $6 \mathrm{~h}$ or 1 or $2 \mathrm{~d}$ of incubation. (B) Scube2 dramatically increases release of signaling activity from cells expressing ShhNp but not ShhN. The signaling activity of the medium was measured at 20-fold dilution using Shh-LIGHT2 cells. The signaling activity of the control conditioned medium was used for normalization. Immunoblotting of medium and whole-cell lysates using anti-ShhN (ShhN, ShhNp, or ShhNpC25S) and anti-Flag (Scube2-3xFlag) indicates that ShhN does not require Scube2 for its release in the medium and that palmitate modification augments Scube2-mediated release of ShhNp.

ducible expression of Shh and ShhC25S. This was accomplished by inducing expression of these cells for $6 \mathrm{~h}$, then blocking new protein synthesis with cycloheximide, while at the same time adding control conditioned medium or conditioned medium containing soluble Scube2. We then monitored release of $\mathrm{ShhNp}$ into the medium as a function of time.

We noted that, in the absence of Scube2, ShhNpC25S is released into the medium more rapidly than $\mathrm{ShhNp}$ (Fig. 4A, cf. lanes 2,6,10,14 and 1,5,9,13), consistent with previous results reported for an altered form of Drosophila Hh (Hh C85S) that lacks palmitoylation (Chamoun et al. 2001). In contrast, however, we noted that levels of ShhNp increased more rapidly in the medium and decreased more rapidly in cells in the presence of Scube2 (Fig. 4A, cf. lanes $3,7,11,15,19,23$ and 4,8,12,16,20,24). The release index for the N-terminal signaling domain ([ShhNp $]_{\text {medium/ }}$ $\left.[\mathrm{ShhNp}]_{\text {cells }}\right)$, plotted as a function of time (Fig. 4B), thus shows that although the presence of a palmitate adduct is not absolutely required for Scube2-mediated release of ShhNp, its presence significantly accelerates the rate of release.
Palmitate modification of ShhNp enhances interaction with Scube2

To further examine the basis for the effect of the palmitate adduct, we immunopurified ShhNp or ShhNpC25S from detergent-solubilized cells using anti-Shh 5E1 antibody coupled to Affigel beads. These immunocomplexes were then used to precipitate soluble Scube2. We found that Scube2 was precipitated approximately threefold more efficiently by ShhNp as compared with ShhNpC25S when assayed by either immunoblotting or Coomassie stains of precipitated proteins (Fig. 4C). This palmitate-dependent enhancement of the physical interaction between Scube2 and ShhNp seems likely to be the basis for enhanced Scube2-mediated release from cultured cells of ShhNp as compared with ShhNpC25S.

\section{Scube2 mediates in vitro release of ShhNp from detergent-resistant membrane microdomains}

The dually lipid-modified ShhNp protein is associated with detergent-insoluble glycolipid-enriched domains (DIGs) (Taipale et al. 2000), also termed membrane microdomains or lipid rafts. This association has also been demonstrated for ShhNpC25S, which is cholesterol- but not palmitatemodified (Chen et al. 2004). We tested whether Scube 2 can release ShhNp from these lipid microdomains in a cell-free system by incubating DIGs from Shh- or ShhC25S-expressing cells with control or Scube2-containing conditioned medium, then assaying for soluble ShhNp by immunoblotting or signaling assays (Fig. 5A). We found that $3 \mathrm{~h}$ or $18 \mathrm{~h}$ of incubation with Scube2-containing medium significantly increased the amount of ShhNp released from DIGs in soluble form (Fig. 5B, cf. lanes 4,10 and 3,9) and also increased the amount of soluble signaling activity. In contrast, the level of soluble ShhNpC25S was not increased by incubation with Scube2 (Fig. 5B, cf. lanes 6,12 and 5,11). These results are consistent with our previous experiments demonstrating enhancement of Scube2-mediated release by palmitate modification and further demonstrate that Scube 2 activity can be assayed in a cell-free context in vitro.

\section{The soluble ShhNp released by Scube2 is dually lipid-modified}

Scube2 can overcome cholesterol-mediated membrane tethering of ShhNp, and this Scube2-mediated release is enhanced by palmitate modification, suggesting that Scube 2 may exert its effects primarily on mature, dually lipid-modified ShhNp. To test this hypothesis, we examined the modified state of soluble protein released by Scube2 from ShhNp-expressing cells using conditions previously established for reverse-phase HPLC analysis on a C4 matrix (Chamoun et al. 2001). Under these conditions, we are able to distinguish unmodified ShhN, ShhN proteins singly modified by either cholesterol or palmitate, and dually modified ShhN (Supplemental Fig. 3).

To obtain sufficient protein quantities for chromatography, we used immunoprecipitation to concentrate ShhNp from medium incubated with cells transfected for expres- 
A

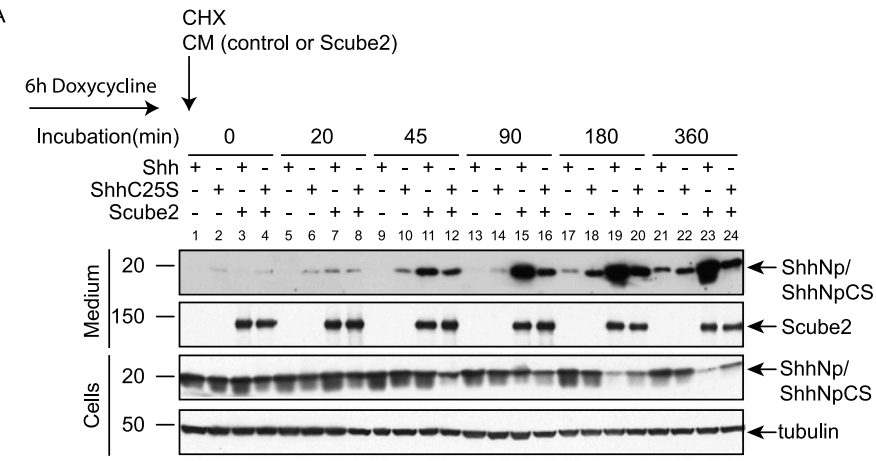

B

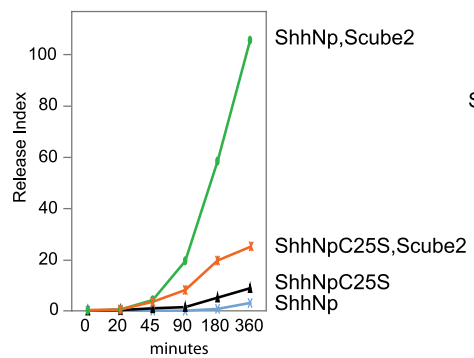

C Scube2 conditioned media

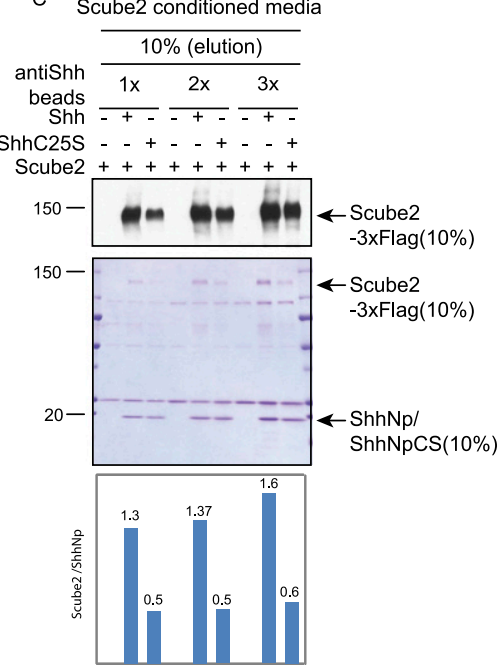

Figure 4. Palmitate modification of ShhNp enhances Scube2-mediated release and contributes to the interaction between ShhNp and Scube2. (A) Time course of Scube2-mediated ShhNp release from cells expressing Shh or ShhC25S. HEK293 Flp-In T-REX cells with stably integrated constructs for tetracycline-inducible expression of Shh or ShhC25S were treated for $6 \mathrm{~h}$ with doxycycline, and medium was replaced with control or Scube2-conditioned medium containing $50 \mu \mathrm{g} / \mathrm{mL}$ cycloheximide. Medium and whole-cell lysates harvested at the indicated time points were immunoblotted with anti-ShhN antibody (ShhN) and anti-Flag (Scube2$3 \times$ Flag), with tubulin as a loading control. The migration of the molecular markers is indicated. $(B)$ Autoradiograms in $A$ were quantified using ImageJ, and the release index ([ShhNp $\left.]_{\text {medium }} /[\mathrm{ShhNp}]_{\text {cells }}\right)$ was plotted for ShhNp and ShhNpC25S in the presence or absence of externally added Scube2. $(C)$ The palmitoyl adduct of ShhNp increases binding of Scube2. Control, Shhexpressing, or Shh C25-expressing HEK293 Flp-In T-Rex cells were lysed in radioimmunoprecipitation assay (RIPA) buffer (see the Materials and Methods), and lysates were incubated for $12 \mathrm{~h}$ with increasing quantities $(1 \times, 2 \times$, and $3 \times)$ of anti-Shh antibody (5E1) immobilized on Affigel 10 beads. Beads were washed and incubated for $4 \mathrm{~h}$ with Scube2-containing medium, and precipitated proteins were eluted with denaturing sample buffer and analyzed by SDS/PAGE followed by immunoblotting (top panel) or Coomassie staining (middle panel). (Bottom panel) Quantification of Scube2-3xFlag and ShhNp/ShhNpC25S from scanned, Coomassie-stained gels with ImageJ software showed that Scube2 is more efficiently precipitated from medium by beads loaded with ShhNp as compared with ShhNpC25S. sion of Shh and either containing or lacking Scube2. As previously noted, the use of medium containing Scube2 significantly increased the level of ShhNp and the signaling activity in the medium. The immunoprecipitations made use of Affigel beads conjugated with the anti-Shh monoclonal antibody 5E1 and were judged to be effective based on the presence of the majority of ShhNp in the pellets and by its depletion from the medium, with the latter assessed by both signaling assays and immunoblotting (Fig. 6A,B).

ShhNp immunoprecipitated from medium was recovered from the Affigel-5E1 matrix by detergent elution and acetone precipitation and then subjected to reverse-phase HPLC analysis. We noted that the majority of the ShhNp from medium lacking Scube2 eluted in fractions characteristic of single modification by cholesterol, with a minority of the protein eluting as a dually modified species (Fig. 6C, top). In sharp contrast, although a similar level of ShhNp single modification by cholesterol was present in the Scube2-containing medium, the great majority of the protein eluted like ShhNp dually modified by cholesterol and palmitate (Fig. 6C, bottom). Our analysis shows that although some dually modified $\mathrm{ShhNp}$ is released in soluble form from cultured cells, Scube2 in the medium can specifically increase the amount of soluble, dually modified ShhNp that is released.

\section{Scube2-mediated release of ShhNp is facilitated by Dispatched}

The role of the Disp protein in the release of cholesterolmodified Hh proteins from producing cells is well established in Drosophila and vertebrates (Burke et al. 1999; Caspary et al. 2002; Kawakami et al. 2002; Ma et al. 2002; Nakano et al. 2004). In order to examine the role of Disp in Scube2-mediated release, we made use of mouse embryonic fibroblasts (MEFs) derived from Disp $A^{-/-}$mutant embryos (Ma et al. 2002). These cells were retrovirally transduced in two stages (Fig. 7A). In the first stage, cells were transduced with a virus containing an expression cassette for Shh linked by an internal ribosome entry site (IRES) to GFP or with the parental retrovirus containing IRES-GFP alone. Positive selection by FACS for GFP expression was used to ensure viral transduction and eliminate cells in the top $5 \%$ or the bottom $5 \%$ of GFP expression. In the second step of transduction, these cells were transduced with a virus containing an expression cassette for DispA linked by an IRES to CD8 or with the parental retrovirus containing IRES-CD8 alone. Positive selection by FACS for CD8 expression was again used to ensure viral transduction and eliminate cells in the top 5\% or the bottom $5 \%$ of CD8 expression. From these sequential transductions, cell populations expressing Shh alone, 
A
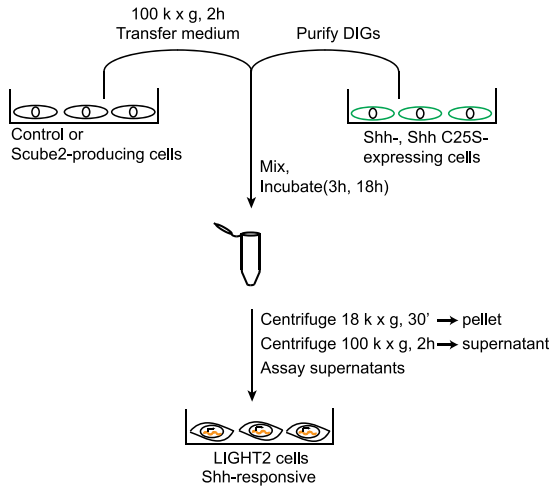

B

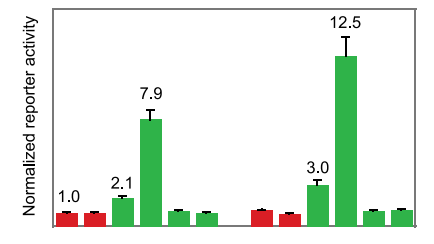

$3 \mathrm{~h}$ Shh $-++\cdots-$

ShhC25S - - - + + - - - + +

Scube2 - + + - + - + + - +

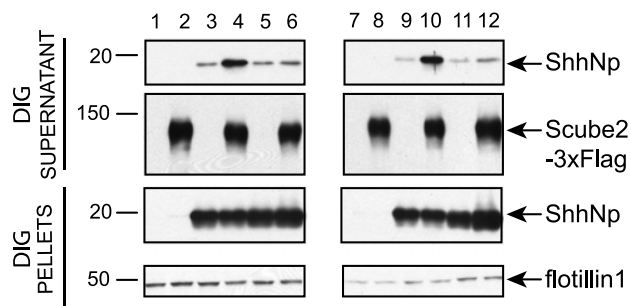

DIGs:Detergent Insoluble Glycolipid Complexes(Rafts)

Figure 5. Scube2 increases the release of ShhNp from lipid rafts in a cell-free assay. (A) Experimental scheme to test for Scube2mediated release of ShhNp protein in a cell-free assay. Lipid rafts (DIGs) isolated from HEK293 Flp-In T-REX cells expressing Shh or ShhC25S were purified by sucrose gradient fractionation and incubated with control or Scube2-containing conditioned medium prepared without serum for the indicated periods of time. (B) Signaling activities of supernatants obtained by incubation of ShhNp- or ShhNpC25S-containing lipid rafts with control or Scube2-containing conditioned medium for $3 \mathrm{~h}$ or $18 \mathrm{~h}$ and centrifuged at $100,000 \mathrm{~g}$ for $2 \mathrm{~h}$ were analyzed with Shh-LIGHT2 cells at threefold dilution. DIG pellets and supernatants were probed for ShhNp (anti-ShhN) and Scube2-3xFlag (anti-Flag) by immunoblotting, with DIG pellets probed also for Flotillin-1 as loading controls. The migration of the molecular markers is indicated. Scube2-containing conditioned medium increases the signaling activity of ShhNp supernatants up to fourfold, and the presence of palmitate modification increases the Scube2-mediated release of ShhNp protein from DIGs in a cell-free assay.

Disp alone, or Shh and Disp together were cultured for further analysis and incubated with medium containing or lacking Scube2.

We found that cells lacking Disp function released only minimal levels of ShhNp protein and signaling activity, even in the presence of Scube2 (Fig. 7B, lanes 3,4), as com- pared with cells expressing DispA and incubated in the presence of Scube2 (Fig. 7B, lane 6). We conclude from these results that Scube2-mediated release of soluble ShhNp from cultured cells is facilitated by the action of Disp.

This apparent role of Disp in facilitating Scube2-mediated release of soluble ShhNp raises the question of whether Disp is expressed and active in HEK293 cells, where we carried out previous assays of Scube2 action (see above). We indeed noted the presence of DispA mRNA in HEK293 cells by RT-PCR (data not shown). To determine whether this mRNA produces functional Disp protein, we introduced DispA-AAA (Fig. 7C), a form of DispA altered in residues known to be critical for Disp function (Ma et al. 2002) and reported to exert a negative trans-dominant effect on wild-type Disp when overexpressed (Etheridge et al. 2010). We noted that DispA-AAA cotransfection with Shh indeed reduced the level of soluble ShhNp and signaling activity released from HEK293 cells in either the presence or absence of Scube2 added to the medium (Fig. 7D, cf. lanes 3,4 and 1,2$)$.

\section{Structural determinants required for Scube2 function in releasing $\operatorname{ShhNp}$}

Previous studies showed that Scube2 can interact with ShhN via the CUB domain (Tsai et al. 2009) and that secretion of Scube2 is mediated by the spacer region C-terminal to the EGF repeats and by the Cys-rich domain preceding the CUB domain (Yang et al. 2002; Tsai et al. 2009). With a series of Scube2 truncation alleles (Fig. 8A; Supplemental Fig. 4), we confirmed that the spacer and Cys-rich repeats contribute to secretion from expressing cells (Fig. 8B; Supplemental Fig. 4). Also consistent with previous findings that the CUB domain can interact with ShhN, we found that the CUB domain was essential for release of ShhNp protein and signaling activity (Fig. 8B). The minimal construct sufficient for function in our ShhNp release and signaling assays was Scube2 $\Delta E G F$, which contains the spacer region, the Cys-rich domains, and the CUB domain (Fig. 8A,B).

We tested our observation from cell culture that EGF repeats are not required for Scube2 activity in Hh signaling in vivo by performing a functional assay in zebrafish for zShh signaling activity. Zebrafish you mutants lack myod expression in adaxial mesoderm cells, which is indicative of a loss of zShh signaling (Lewis et al. 1999; Woods and Talbot 2005; Hollway et al. 2006). We injected mRNA encoding wild-type or truncated forms of zScube2 lacking the EGF repeats into embryos from you/+ intercrosses and examined myod expression in adaxial mesoderm cells (Fig. 8C). We found that all embryos homozygous for you $(n=26)$ lacked myod expression in adaxial cells at the 12-somite stage (Fig. 8C, left column). When injected with $50 \mathrm{pg}$ of wild-type zscube2 mRNA, 100\% $(n=29)$ of embryos homozygous for you showed rescued expression of myod in adaxial cells (Fig. 8C, middle column). Similarly, $93 \%$ ( $n=60$ ) of you mutant embryos that were injected with $50 \mathrm{pg}$ of zscube2 $\triangle E G F$ mRNA showed wild-type expression of myod in adaxial cells (Fig. 8C, right column). Thus, the zScube2 construct lacking the EGF 
A

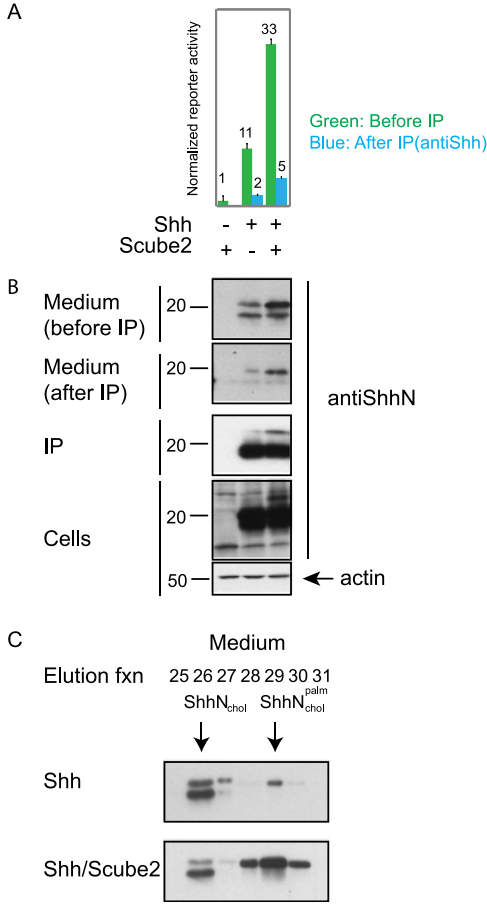

Figure 6. Soluble ShhNp released by Scube2 is dually lipidmodified. (A) HEK293S cells transiently transfected $(24 \mathrm{~h})$ with expression plasmids for 3xFlag-tagged Scube 2 or control plasmid along with Shh (2:1 ratio) were incubated for $4 \mathrm{~d}$ with medium lacking transfection reagent. After harvesting, medium was centrifuged at 100,000 $\mathrm{g}$ for $2 \mathrm{~h}$ and incubated with immobilized anti-ShhN (5E1 antibody linked to Affigel 10 beads) for $24 \mathrm{~h}$. The signaling activity of the medium before (green) and after (blue) incubation with anti-ShhN beads was analyzed by incubation with Shh-LIGHT2 cells at fivefold dilution. Note that the signaling activity is depleted by incubation with anti-ShhN beads. (B) Culture medium before and after incubation with anti-ShhN beads, immunoprecipitated protein, and whole-cell lysate (with actin as a loading control) was immunoblotted for ShhNp (antiShhN). Note the efficiency of ShhNp depletion from the medium. (C) Lipid modification of ShhNp as determined by reverse-phase HPLC. ShhNp immunoprecipitated from conditioned medium as in $B$ was analyzed by reverse-phase HPLC in a C4 column developed with a gradient of increasing acetonitrile in water containing $0.1 \%$ trifluoroacetic acid to determine the degree of ShhN lipid modification. Fractions eluted from reverse-phase HPLC were analyzed by immunoblotting after vacuum-drying and resolubilization with $1 \times$ protein sample buffer. Representative elution fractions are shown, and elution standards were characterized by reverse-phase HPLC analysis of ShhNp, ShhNpC25S, ShhN, and ShhNC25S proteins (Supplemental Fig. 3). ShhNpconditioned medium prepared in the presence of Scube2 contains increased levels of dually lipidated $\mathrm{ShhNp}\left(\mathrm{Shh}_{\mathrm{chol}}^{\text {palm }}\right)$

repeats was as effective as wild-type zScube2 in rescuing adaxial myod expression in you mutants.

\section{Discussion}

Scube2/you acts by mediating the release of Hh proteins

A genetic screen published $>15$ years ago identified a group of zebrafish mutants characterized by the abnormal
U-shaped appearance of somites due to defects in the specification of slow muscle fibers and the absence of horizontal myoseptum. These mutants, named you class mutants, were eventually shown to disrupt embryonic Hedgehog signaling, as first suggested by the demonstration that the sonic-you (syu) mutant inactivates the zebrafish sonic hedgehog gene (Schauerte et al. 1998). Other genes disrupted in you class mutants (you-too, chameleon, and slow muscle-omitted) were found to encode known components of the Hh pathway previously identified in Drosophila (Cubitus interruptus, dispatched, and smoothened, respectively) (Karlstrom et al. 1999; Chen et al. 2001; Varga et al. 2001; Nakano et al. 2004). The eponymous you mutant of this class, however, has no Drosophila ortholog (Kawakami et al. 2005; Woods and Talbot 2005; Hollway et al. 2006), and the molecular mechanism of its function in vertebrate Hedgehog signaling remained elusive.

Given that you appears to encode a secreted protein and that rescuing function of the $\mathrm{you}^{+}$gene could be supplied from cells that neither produce nor respond to Hh signals (Woods and Talbot 2005), we tested the possibility that the $\mathrm{yOu}^{+}$protein may act cell-nonautonomously in mediating the release of the lipid-modified Hedgehog protein. Indeed, we found that the Scube 2 protein encoded by a mammalian ortholog of you can stimulate the release of ShhNp into the medium of cultured cells expressing Shh. This enhanced release of ShhNp in soluble form was detected by increased protein levels and signaling activity in culture medium conditioned by cells expressing Shh; the Scube2 protein could be provided by either cotransfecting Scube2 with Shh or adding soluble Scube2 protein to the medium of Shh-expressing cells. Importantly, Scube2 was unable to stabilize ShhNp or enhance the responsiveness of stimulated cells.

Our results support a conclusion distinct from that of a previous report, which suggested that Scube2 acts to enhance Shh response (Tsai et al. 2009). These previous experiments showed increased pathway activity when Shh-LIGHT2 cells transfected with Shh were additionally cotransfected with Scube2, but did not distinguish between Scube2 expression in Shh-producing or responding cells; our experiments now clearly show that Scube2 has its effect only when it is present with cells expressing Shh and not if it is present only with responding cells. Our results are fully consistent with the zebrafish data demonstrating that $\mathrm{you}^{+} / \mathrm{Scube} 2$ function can rescue you mutant embryos when supplied from cells that do not respond to Hh signals (Woods and Talbot 2005). Further support for $\mathrm{ShhNp}$ release as the major mode of Scube2 action in $\mathrm{Hh}$ signaling is provided by our structure/function analysis (Fig. 8), in which Scube2-mediated release of soluble ShhNp from cultured cells in vitro is strongly correlated with the ability to rescue the you mutant phenotype in vivo.

\section{Mechanism of Scube2 action}

Covalent linkage of the mature Hh signal to both palmitate and cholesterol raises the question of how the longrange action of a morphogenic protein bearing dual lipid modifications is achieved. We therefore investigated the 

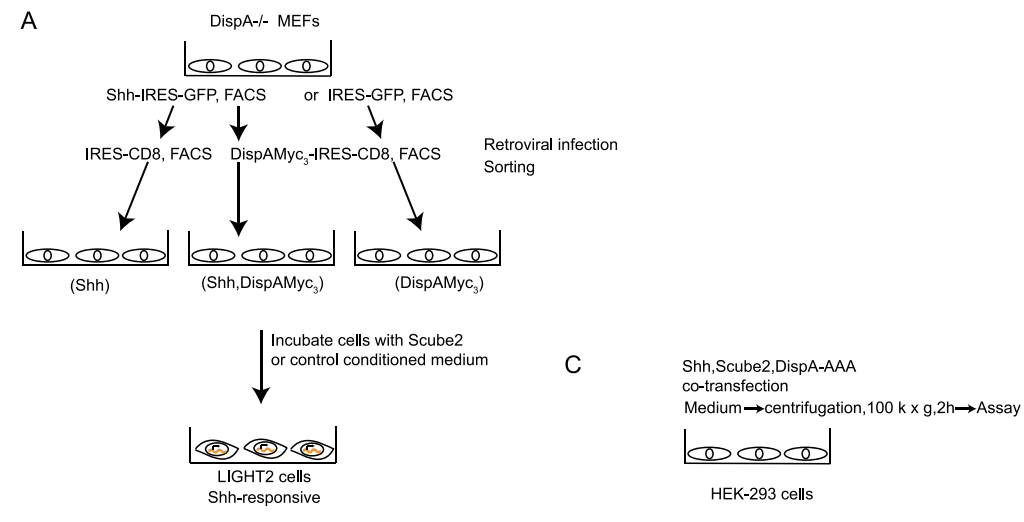

B
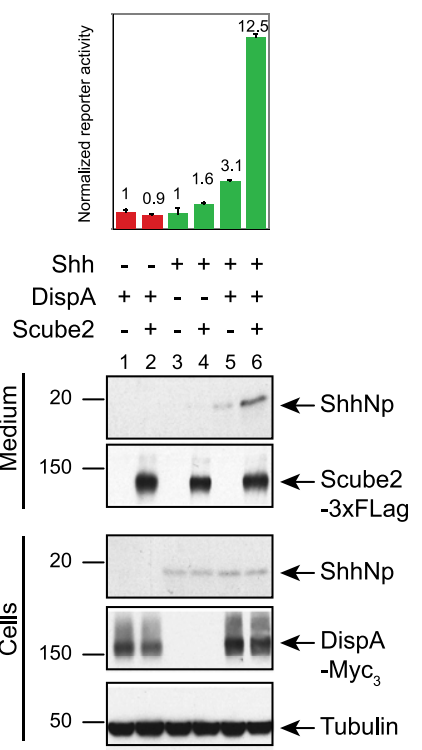

D

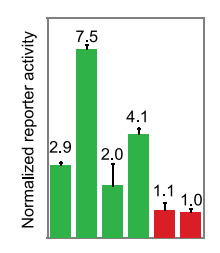

$+++-$

-+++ DispA-AAA

-++++ Scube2

$\begin{array}{llllll}1 & 2 & 3 & 4 & 5 & 6\end{array}$
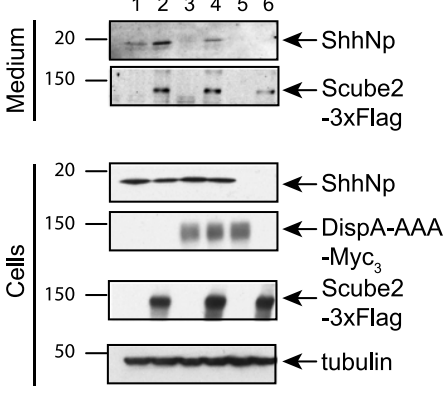

Figure 7. Scube2-mediated release of ShhNp is facilitated by Dispatched. $(A)$ Experimental scheme to test for the role of DispA in the Scube2-mediated release of ShhNp. Disp $A^{-/-}$MEF cells transduced with a MIGR1 retrovirus-based construct expressing Shh-IRES-GFP or IRES-GFP were FACS-sorted for GFP. Next, GFP+ cells were transduced with DispAIRES-CD8 or IRES-CD8 and FACS-sorted for CD8. These cells were incubated with control or Scube2containing conditioned medium for $2 \mathrm{~d}$. (B) Scube 2 stimulates the release of $\mathrm{ShhNp}$ protein and signaling activity only in the presence of DispA. The signaling activity of media collected from Disp $A^{-/-}$ cells transduced with the indicated expression constructs and incubated with Scube2- or control conditioned medium was analyzed with Shh-LIGHT2 cells at twofold dilution. Media and whole-cell extracts were probed for ShhNp (anti-ShhN), 3xFlag-tagged Scube2 (anti-Flag), and 3xMyc-tagged DispA (antiMyc) by immunoblotting, with tubulin used as a loading control. The migration of the molecular markers is indicated. In the presence of DispA, Scube2-containing conditioned medium increased signaling activity by approximately fourfold and increased the level of released ShhNp detectable by immunoblotting. $(C)$ Experimental scheme to test effect of the DispA-AAA dominant-negative. HEK293S cells cultured in six-well plates were transiently transfected with $1: 6: 15(\mathrm{w} / \mathrm{w} / \mathrm{w})$ ratios of plasmids expressing Shh, Scube2, and DispA-AAA, respectively. The signaling activities of medium collected $4 \mathrm{~d}$ post-transfection were analyzed by incubation with Shh-LIGHT2 cells. $(D)$ Scube2-mediated release of ShhNp in the medium is reduced by expression of DispA-AAA. Signaling activities of media samples were measured with Shh-LIGHT2 cells at fivefold dilution. Culture medium and whole-cell lysates were probed by immunoblotting for expression of ShhNp (anti-ShhN antibody), 3xFlag-tagged Scube2 (anti-Flag antibody), and 3xMyc-tagged DispA-AAA (anti-Myc antibody). Note that the signaling activity and the release of ShhNp into the medium were decreased by coexpression of DispA-AAA.

covalent state of ShhNp in its soluble, active form, as released by Scube2, using HPLC separation to indicate hydrophobicity and the extent of lipid modification. We found that the bulk of ShhNp released by Scube2 is dually lipidmodified; in fact, our evidence indicates that $\mathrm{N}$-terminal acylation of ShhNp actually plays a positive role in Scube2-mediated release of ShhNp in a soluble, active form (see below). How the hydrophobic character of dual lipid adducts is accommodated in the soluble form of ShhNp released by Disp/Scube remains to be determined. One possibility is the formation of a micelle-like complex with a hydrophobic core of interacting lipids, as previously suggested (Zeng et al. 2001; Chen et al. 2004).

Some reports have suggested that the release and activity of modified Hh proteins is dependent on sheddasemediated removal of $\mathrm{N}$-terminal amino acids and palmitate (Dierker et al. 2009; Ohlig et al. 2011). The Disp/Scubemediated mechanism of release we describe here is distinct from this view of Shh signal activation by a sheddase (Dierker et al. 2009; Ohlig et al. 2011) in that (1) the form of the signal released by Disp/Scube retains its $\mathrm{N}$-terminal amino acids and palmitate adduct, and (2) the presence/ absence of Scube modulates release of ShhNp by 10 -fold to 20-fold (Figs. 2D, 3B, 4B) as compared with an approximately twofold change in the presence/absence of sheddases (Dierker et al. 2009; Ohlig et al. 2011). We note that the retention of palmitate and $\mathrm{N}$-terminal amino acids in the Disp/Scube-mediated mechanism we characterize is consistent with previous studies demonstrating a high signaling activity for purified, $\mathrm{N}$-terminally acylated forms of the Shh signal (Pepinsky et al. 1998; Taipale et al. 2000). Sheddase-mediated removal of $\mathrm{N}$-terminal amino acid residues and palmitate from ShhNp is an intriguing mode of possible regulation, but establishing its physiologic or pathological significance in Hh signaling may require genetic analysis like that for you in the zebrafish, which clearly indicates a physiological function for Scube proteins in vertebrate Hh signaling.

Previous work has shown that Dispatched plays a critical role in the mobilization of the Hedgehog signal in vivo (Burke et al. 1999; Caspary et al. 2002; Kawakami et al. 2002; Ma et al. 2002; Nakano et al. 2004), and some 


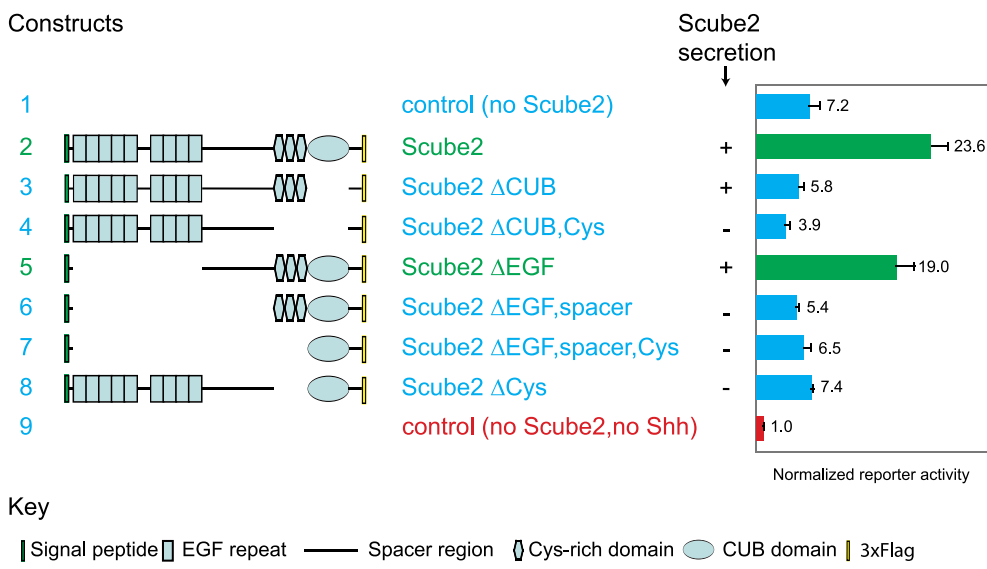

C

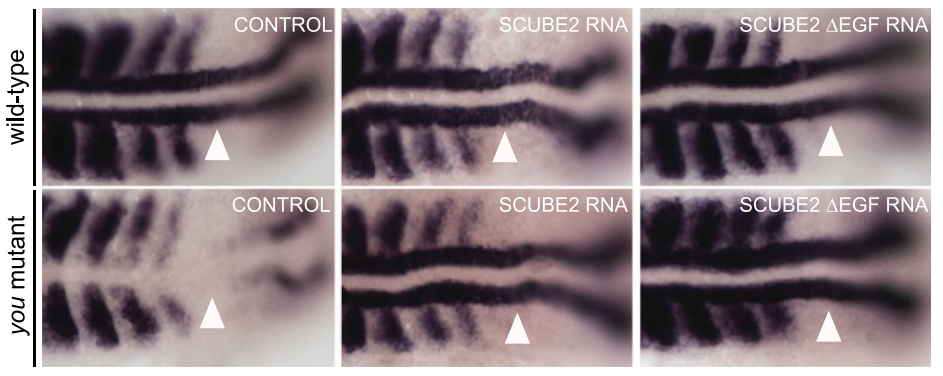

Figure 8. Structure-function analysis of Scube2 function in vitro and in vivo. $(A)$ Schematic diagram shows $3 x$ Flag-tagged Scube 2 deletion constructs used for this analysis. $(B)$ Signaling activity of medium from HEK293S cells transiently cotransfected with expression plasmids for Shh and wild-type or deleted $3 \times$ Flag-tagged Scube2 (1:2 ratio) was measured with ShhLIGHT2 cells at fivefold dilution. For immunoblotting analysis of these samples, see Supplemental Figure 4. Secretion of Scube2 protein variants into culture medium as detected by immunoblotting is indicated $(+$ or -$)$. $(C)$ Rescue of you mutants by microinjection of zscube2 mRNA constructs. (Top row) Wild-type embryos show adaxial expression of myod (white arrowheads). (Bottom left) You mutant embryos lack adaxial myod expression (white arrowhead). Injection of full-length zscube2 mRNA (middle column) and zscube2 $\Delta E G F$ mRNA (right column) rescues the expression of myod in adaxial cells in you mutants (white arrowheads). evidence has been presented for the action of Dispatched in releasing ShhNp from cultured cells in a soluble form in vitro (Ma et al. 2002). A more recent report suggests that Dispatched acts by facilitating the transfer of modified ShhNp directly from one cell to another (Etheridge et al. 2010). This requirement for cell-cell contact in Disp function is not supported by Drosophila genetic studies, which clearly demonstrate a requirement for disp function exclusively in Hh-producing cells (Burke et al. 1999). Our studies further demonstrate that mammalian Disp can contribute to the Scube2-mediated release of a soluble, active form of the ShhNp protein in the absence of cellcell contact. The cell contact-dependent mechanism of Disp-mediated release suggested by Etheridge et al. (2010) nevertheless could operate in some biological settings. The absence of a Scube ortholog in Drosophila suggests that the activity of Dispatched in mediating the release of the Drosophila Hh signal may be independent of a Scube ortholog, possibly due to the unique composition of Drosophila detergent-insoluble lipid microdomains (Rietveld et al. 1999).

\section{The importance of palmitate modification}

The importance of palmitate modification for Scube2 release of $\mathrm{ShhNp}$ is suggested by the dramatic difference in Scube2 enhancement of ShhNp release from cells expressing wild-type Shh as compared with ShhC25S (Figs. $3,4 \mathrm{~A}, \mathrm{~B})$. This difference extends to our cell-free assay, in which Scube2-mediated release of ShhNp from DIGs depends critically on the presence of palmitate for optimal efficiency (Fig. 5B). The mechanistic basis of this difference is suggested by more efficient binding of Scube2 to immobilized ShhNp as compared with immobilized ShhNpC25S (Fig. 4C); improved release of acylated ShhNp thus appears to be stimulated by favorable binding interactions between Scube2 and the acyl chain modification of ShhNp, although we note that Scube2 also shows reasonable albeit lower affinity for ShhNpC25S, which lacks acylation (Fig. 4C).

These results are consistent with and account for previously reported observations that the palmitate group not only enhances ShhNp potency (Pepinsky et al. 1998; Chamoun et al. 2001; Kohtz et al. 2001; Lee and Treisman 2001; Micchelli et al. 2002; Chen et al. 2004), but also facilitates the release or transport of ShhNp in the extracellular milieu (Chen et al. 2004; Chamberlain et al. 2008). The experiments in Chamberlain et al. (2008) are particularly striking, as they demonstrate that $\mathrm{ShhNp}$ produced in the notochord can spread through the extracellular matrix, traverse the neuroepithelium, and enter the lumen of the neural tube; the Shh protein is unable to do so, however, when acylation of ShhNp is disrupted by mutation of the Skn acyltransferase (Chen et al. 2004; Chamberlain et al. 2008).

Given the importance of palmitoylation in the release and movement of the ShhNp protein, it is interesting to note that Wnt proteins are palmitoylated and that, at least in Drosophila, EGF proteins are also palmitoylated 
(Willert et al. 2003; Miura et al. 2006; Takada et al. 2006). Recently, Mulligan et al. (2012) showed that Swim, a secreted Wingless (Wg)-interacting molecule, augments longrange Wg signaling in Drosophila imaginal discs and demonstrated that Swim acts by maintaining the solubility of lipid-modified $\mathrm{Wg}$ in the medium. This finding supports the hypothesis that lipid-modified morphogens may use additional factors for their release into and transport through the hydrophilic extracellular milieu. Interestingly, our structure/function analysis of Scube2 indicates that the EGF repeats are dispensable for release of $\mathrm{ShhNp}$ in vitro and for Hh pathway function in vivo. These repeats thus could be involved in activities other than the release of ShhNp; as the Scube2 $\triangle \mathrm{EGF}$ construct lacking these repeats remains active in releasing acylated $S h h N p$, it is conceivable that these other activities may involve other acylated proteins.

\section{Materials and methods}

\section{DNA constructs}

All constructs used for cell culture experiments were built using mouse sequences. Constructs expressed in mammalian HEK293S cells were cloned into the pcDNA3.1 vector (Invitrogen) that contains the CMV promoter. Shh constructs in pcDNA3.1 were generated by PCR amplification and subcloning of a restriction fragment digested with Not1 and Xhol.

Full-length $\mathrm{mScube} 2$ was built using two distinct cDNA clones (BC152820.1 and NM_020052) to have a domain architecture similar to that of $z$ Scube2 (NP_001014813). mScube2 expression constructs were tagged at the $\mathrm{C}$ terminus with the $3 \mathrm{xFlag}$ epitope or $1 \mathrm{xMyc}$. Of note, the mScube 2 construct lacking amino acids 171-281-including a putative furin cleavage site, R(274)XKRRretains the entire activity of full-length $\mathrm{mScube2}$. Constructs expressing either GFP or mWIF-1 were used as transfection controls with similar results. The mWIF-1 cDNA, NM_011915.2, expression construct in pcDNA3.1 was generated by PCR amplification and subcloning of a restriction fragment digested with Not1 and Xhol.

Constructs expressed in HEK293 Flp-In cells were built in pcDNA5/FRT/TO vector (Invitrogen) by PCR amplification and subcloning of a restriction fragment digested with Not1 and Xhol.

Constructs expressed in Disp $A^{-/-}$MEFs were cloned into MIGR vector. mDispA cDNA optimized for protein expression was amplified by PCR and subcloned after digestion with Xhol into MIGR-CD8, which contains a multiple cloning site followed by an IRES-CD8 cassette. Sonic hedgehog cDNA was cloned into MIGR-GFP, which contains an IRES-GFP cassette downstream from the multiple cloning site.

Constructs used to synthesize mRNA for zebrafish embryo injections were built in $\mathrm{pCS}^{+}$that contains a SP6 promoter. PCR products of Myc-tagged zScube2 and zScube2 $\triangle$ EGF were digested with Xhol and Xbal.

\section{Cell culture and Hh reporter assay}

HEK293S (American Type Culture Collection [ATCC]) cells were grown in DMEM supplemented with $10 \%$ (v/v) FBS (Invitrogen). NIH-3T3 and Shh-LIGHT2 cells were grown in DMEM supplemented with $10 \%(\mathrm{v} / \mathrm{v})$ bovine calf serum (Atlanta Scientific).

$D_{i s p} A^{-1-}$ MEFs (Ma et al. 2002) were grown in DMEM supplemented with $10 \%$ (v/v) FBS.
HEK293 Flp-In T-REX cells (Invitrogen) were used to generate isogenic stable cell lines. HEK293 Flp-In T-REX cells were grown in DMEM supplemented with $10 \%(\mathrm{v} / \mathrm{v})$ FBS tetracycline-free (Clontech), blasticidin (15 $\mu \mathrm{g} / \mathrm{mL}$; Invitrogen), and Zeocin (100 $\mu \mathrm{g} / \mathrm{mL}$; Invitrogen). Hygromicin (75 $\mu \mathrm{g} / \mathrm{mL}$; Roche) was used to select stably transfected cells. Doxycycline $(1 \mu \mathrm{g} / \mathrm{mL}$; Sigma) was used to induce expression of inserted genes. Cycloheximede $(50 \mu \mathrm{g} /$ $\mathrm{mL}$; Sigma) was used to inhibit protein biosynthesis in these cells.

Scube2-conditioned medium was prepared by incubation of HEK293 Flp-In T-REX cells carrying a stably integrated Scube2$3 x$ Flag expression construct with DMEM (Invitrogen) containing $2 \%$ FBS and doxycycline ( $1 \mu \mathrm{g} / \mathrm{mL}$; Sigma) for $48 \mathrm{~h}$. HEK293 FlpIn T-REX parental cells were used to prepare control conditioned medium using a medium formulation identical to that for Scube2conditioned medium. Of note, similar results were used when FBS was omitted from the medium.

Hh signaling assays were carried out using Shh-LIGHT2 cells. Hh-conditioned medium prepared as indicated was incubated with confluent Shh-LIGHT2 cells growing in 24-well plates for 36-48 h. Luciferase activities were measured using Dual-Luciferase Reporter assay (Promega) and a Centro XS3 (Berthold) luminometer.

\section{Retroviral infection}

Disp $A^{-1-}$ MEF cells with an integrated MIGR1 vector expressing either GFP or Shh linked by an IRES to GFP were generated by retroviral infection followed by FACS selection of GFP-expressing cells. The viral supernatants were obtained by harvesting media from Phoenix ampho packaging cells transfected with MIGR1 IRES-GFP or MIGR1 Shh-IRES-GFP expression constructs. Disp $A^{-/-}$MEF cells were plated at a density of $10 \%$ cells per well of 24-well plates, and $24 \mathrm{~h}$ later, cells were transduced with the viral supernatants using spin infection at $2000 \mathrm{~g}$ for $1 \mathrm{~h}$ at $30^{\circ} \mathrm{C}$ with $6 \mu \mathrm{g} / \mathrm{mL}$ polybrene (Sigma).

Disp $A^{-1-}$ MEF cells with stably integrated IRES-GFP or ShhIRES-GFP expression cassettes were transduced with a virus containing an expression cassette for DispA linked by an IRES to CD8 or with the parental retrovirus containing IRES-CD8 alone using the procedure described above followed by FACS selection of CD8-expressing cells.

\section{Western blotting}

Protein expression analysis of cultured cells transfected with expression plasmids using Fugene HD (Roche) were performed by harvesting cells and conditioned medium for reducing SDSPAGE and immunoblotting. Whole-cell protein extracts were prepared by solubilization in radioimmunoprecipitation assay (RIPA) buffer containing $1 \%$ NP-40, $0.5 \%$ sodium deoxycholate, $0.1 \%$ SDS, 50 mM Tris- $\mathrm{HCl}$ (pH 7.5), $150 \mathrm{mM} \mathrm{NaCl}, 1$ mM EDTA, and protease inhibitor cocktail (Roche). Medium was spun for 30 min at $18,000 \mathrm{~g}$ to remove cell debris (followed, when mentioned, by an additional centrifugation at 100,000 $g$ for $2 \mathrm{~h}$ ). Samples from both cell lysates and medium were mixed with sample buffer (Fermentas) containing DTT (50 $\mathrm{mM}$ final concentration) and analyzed by reducing SDS-PAGE followed by immunoblotting. Antibodies used for this study were as follows: anti-ShhN rabbit polyclonal (Porter et al. 1996b), anti-Flag M2 mouse monoclonal (Sigma), anti-HA (Covance), anti-tubulin mouse monoclonal (E2, ATCC), anti-CD8 coupled with Alexa 647 (BD Pharmingen), and anti-actin mouse monoclonal (Santa Cruz Biotechnology).

\section{Lipid raft isolation}

Lipid rafts (DIGs) were isolated from control, Shh-expressing, and ShhC25S-expressing HEK293 Flp-In T-REX cells. Cells were 
grown in 150-mm dishes and lysed in buffer containing $10 \mathrm{mM}$ $\mathrm{NaH}_{2} \mathrm{PO}_{4}$ (pH 6.5), $150 \mathrm{mM} \mathrm{NaCl}, 1 \%$ Triton X-100, and a cocktail of protease inhibitors at $4{ }^{\circ} \mathrm{C}$ (Taipale et al. 2000). Wholecell extracts were then mixed with the same volume of $80 \%$ sucrose to generate $40 \%$ sucrose lysate solution. Two sucrose density steps, $16.5 \mathrm{~mL}$ of $36 \%$ sucrose and $7 \mathrm{~mL}$ of $5 \%$ sucrose, were layered onto $14 \mathrm{~mL}$ of $40 \%$ sucrose lysate, and centrifugation was carried out in a Beckman Ti45 rotor at 35,000 rpm for $24 \mathrm{~h}$ at $4^{\circ} \mathrm{C}$. Raftcontaining fractions were visually identified and collected. Sucrose from these fractions was diluted by adding 4 vol of phosphatebuffered saline (PBS) (10 mM NaH $\mathrm{PO}_{4}$ at $\mathrm{pH}$ 6.5, $150 \mathrm{mM} \mathrm{NaCl}$ ), and rafts were precipitated by centrifugation. Rafts were resuspended in PBS and divided in equal volumes into $1.5-\mathrm{mL}$ tubes. PBS was exchanged with Scube2-containing or control conditioned medium by centrifugation. Of note, Scube2-containing or control conditioned medium did not contain serum. After incubations with Scube2-containing or control conditioned medium for the indicated periods of time, rafts were harvested by centrifugation at $18,000 \mathrm{~g}$ for $30 \mathrm{~min}$. After incubation with protein sample buffer containing DTT for $10 \mathrm{~min}$ at $100^{\circ} \mathrm{C}$, rafts were analyzed by SDS-PAGE followed by immunoblotting. Supernatants were centrifuged at $100,000 \mathrm{~g}$ for an additional $2 \mathrm{~h}$, and samples were collected for signaling activity measurements and expression analysis by SDS-PAGE followed by immunoblotting.

Reverse-phase HPLC analysis of mammalian

Hedgehog proteins

HEK293S cells growing in $10-\mathrm{cm}^{2}$ dishes were transfected with expression plasmids for Shh, ShhN, ShhC25S, ShhNC25S, Scube2$3 x F l a g$, or control. Three days post-transfection, media and cells were harvested. Medium (6 mL) was centrifuged at $3000 \mathrm{~g}$ for $30 \mathrm{~min}$ followed by $100,000 \mathrm{~g}$ for $2 \mathrm{~h}$. After centrifugation, medium was incubated overnight with anti-Shh monoclonal antibody (5E1) immobilized on Affigel 10 beads (Bio-Rad). The next day, beads were washed and eluted by incubation with $1 \times$ reducing sample buffer (Invitrogen) for $15 \mathrm{~min}$ at $37^{\circ} \mathrm{C}$. Eluted proteins were acetone-precipitated. Whole-cell protein extracts were prepared from $10-\mathrm{cm}^{2}$ dishes by solubilization with $1 \mathrm{~mL}$ of RIPA buffer containing a cocktail of protease inhibitors (Roche) for $30 \mathrm{~min}$ at $4^{\circ} \mathrm{C}$. After centrifugation at $18,000 \mathrm{~g}$ for $30 \mathrm{~min}$ to remove insoluble material, $100 \mu \mathrm{L}$ of whole-cell protein extract was acetone-precipitated.

Protein precipitates were resuspended with $35 \mu \mathrm{L}$ of $(1,1,1,3,3,3)$ hexafluoro-2-propanol and solubilized with $70 \mu \mathrm{L}$ of $70 \%$ formic acid followed by brief sonication. For reverse-phase HPLC, we used an acetonitrile: water gradient with $0.1 \%$ trifluoroacetic acid and C-4 column. Elution samples were vacuum-dried, resolubilized in $1 \times$ reducing sample buffer, and analyzed by SDS/PAGE (Chamoun et al. 2001).

\section{RNA synthesis and microinjection of zebrafish embryos}

The full-length zscube2 and zscube2 $\Delta E G F$ constructs were linearized with NotI, and mRNA was synthesized using the SP6 mMessage mMachine kit (Ambion). Final RNA was diluted in ultrapure water, and Phenol Red was added to a concentration of $5 \mathrm{mg} / \mathrm{mL}$. The solution was adjusted so that the total mRNA injected into each embryo was $50 \mathrm{pg}$ and the volume injected was $1 \mathrm{~nL}$. After injection, embryos were maintained under standard conditions and staged according to Kimmel et al. (1995).

\section{In situ hybridization and genotyping}

Embryos were dechorionated by hand and then fixed at the 12-somite stage in $4 \%$ PFA overnight at $4^{\circ} \mathrm{C}$. In situ hybridization for myod expression was performed using standard methods (Thisse and Thisse 2008) with an antisense myod probe (Weinberg et al. 1996). Embryos were scored on the basis of myod expression in adaxial cells and were genotyped by PCR (forward primer, AGATCATTGCGGCAGTGGA; reverse primer, GCACCCTT CAATAATCTTCTTCTT) followed by a restriction digest with Hpy8I. The mutant band ran at 200 base pairs (bp), while the wild-type band ran at $185 \mathrm{bp}$.

\section{Acknowledgments}

We thank Masaki Kato, Xiaoyan Zheng, and Ben Myers for their help in completing this project. We also thank Keith Young, Jynho Kim, Navdar Sever, Wenchuan Liang, and Yong Chun Chong for reagents and protocols, and James Chen and Dan Leahy for critical review of the manuscript.

\section{References}

Beachy PA, Karhadkar SS, Berman DM. 2004. Tissue repair and stem cell renewal in carcinogenesis. Nature 432: 324-331.

Briscoe J, Chen Y, Jessell TM, Struhl G. 2001. A hedgehoginsensitive form of patched provides evidence for direct longrange morphogen activity of sonic hedgehog in the neural tube. Mol Cell 7: 1279-1291.

Buglino JA, Resh MD. 2008. Hhat is a palmitoylacyltransferase with specificity for N-palmitoylation of Sonic Hedgehog. I Biol Chem 283: 22076-22088.

Burke R, Nellen D, Bellotto M, Hafen E, Senti KA, Dickson BJ, Basler K. 1999. Dispatched, a novel sterol-sensing domain protein dedicated to the release of cholesterol-modified hedgehog from signaling cells. Cell 99: 803-815.

Caspary T, Garcia-Garcia MJ, Huangfu D, Eggenschwiler JT, Wyler MR, Rakeman AS, Alcorn HL, Anderson KV. 2002. Mouse Dispatched homolog1 is required for long-range, but not juxtacrine, Hh signaling. Curr Biol 12: 1628-1632.

Chamberlain CE, Jeong J, Guo C, Allen BL, McMahon AP. 2008. Notochord-derived Shh concentrates in close association with the apically positioned basal body in neural target cells and forms a dynamic gradient during neural patterning. $D e-$ velopment 135: 1097-1106.

Chamoun Z, Mann RK, Nellen D, von Kessler DP, Bellotto M, Beachy PA, Basler K. 2001. Skinny hedgehog, an acyltransferase required for palmitoylation and activity of the hedgehog signal. Science 293: 2080-2084.

Chen W, Burgess S, Hopkins N. 2001. Analysis of the zebrafish smoothened mutant reveals conserved and divergent functions of hedgehog activity. Development 128: 2385-2396.

Chen MH, Li YJ, Kawakami T, Xu SM, Chuang PT. 2004. Palmitoylation is required for the production of a soluble multimeric Hedgehog protein complex and long-range signaling in vertebrates. Genes \& Dev 18: 641-659.

Dierker T, Dreier R, Petersen A, Bordych C, Grobe K. 2009. Heparan sulfate-modulated, metalloprotease-mediated sonic hedgehog release from producing cells. I Biol Chem 284: 8013-8022.

Etheridge LA, Crawford TQ, Zhang S, Roelink H. 2010. Evidence for a role of vertebrate Disp1 in long-range Shh signaling. Development 137: 133-140.

Eugster C, Panakova D, Mahmoud A, Eaton S. 2007. Lipoprotein-heparan sulfate interactions in the Hh pathway. Dev Cell 13: 57-71.

Grimmond S, Larder R, Van Hateren N, Siggers P, Hulsebos TJ, Arkell R, Greenfield A. 2000. Cloning, mapping, and expression analysis of a gene encoding a novel mammalian EGFrelated protein (SCUBE1). Genomics 70: 74-81. 
Grimmond S, Larder R, Van Hateren N, Siggers P, Morse S, Hacker T, Arkell R, Greenfield A. 2001. Expression of a novel mammalian epidermal growth factor-related gene during mouse neural development. Mech Dev 102: 209-211.

Hollway GE, Maule J, Gautier P, Evans TM, Keenan DG, Lohs C, Fischer D, Wicking C, Currie PD. 2006. Scube2 mediates Hedgehog signalling in the zebrafish embryo. Dev Biol 294: 104-118.

Karlstrom RO, Talbot WS, Schier AF. 1999. Comparative synteny cloning of zebrafish you-too: Mutations in the Hedgehog target gli2 affect ventral forebrain patterning. Genes \& Dev 13: 388-393.

Kawakami T, Kawcak T, Li YJ, Zhang W, Hu Y, Chuang PT. 2002. Mouse dispatched mutants fail to distribute hedgehog proteins and are defective in hedgehog signaling. Development 129: 5753-5765.

Kawakami A, Nojima Y, Toyoda A, Takahoko M, Satoh M, Tanaka H, Wada H, Masai I, Terasaki H, Sakaki Y, et al. 2005. The zebrafish-secreted matrix protein you/scube 2 is implicated in long-range regulation of hedgehog signaling. Curr Biol 15: 480-488.

Kimmel CB, Ballard WW, Kimmel SR, Ullmann B, Schilling TF. 1995. Stages of embryonic development of the zebrafish. Dev Dyn 203: 253-310.

Kohtz JD, Lee HY, Gaiano N, Segal J, Ng E, Larson T, Baker DP, Garber EA, Williams KP, Fishell G. 2001. N-terminal fattyacylation of sonic hedgehog enhances the induction of rodent ventral forebrain neurons. Development 128: 23512363.

Lee JD, Treisman JE. 2001. Sightless has homology to transmembrane acyltransferases and is required to generate active Hedgehog protein. Curr Biol 11: 1147-1152.

Lewis KE, Currie PD, Roy S, Schauerte H, Haffter P, Ingham PW. 1999. Control of muscle cell-type specification in the zebrafish embryo by hedgehog signalling. Dev Biol 216: 469-480.

Li Y, Zhang H, Litingtung Y, Chiang C. 2006. Cholesterol modification restricts the spread of Shh gradient in the limb bud. Proc Natl Acad Sci 103: 6548-6553.

Ma Y, Erkner A, Gong R, Yao S, Taipale J, Basler K, Beachy PA. 2002. Hedgehog-mediated patterning of the mammalian embryo requires transporter-like function of dispatched. Cell 111: $63-75$.

Mann RK, Beachy PA. 2004. Novel lipid modifications of secreted protein signals. Annu Rev Biochem 73: 891-923.

Micchelli CA, The I, Selva E, Mogila V, Perrimon N. 2002. Rasp, a putative transmembrane acyltransferase, is required for Hedgehog signaling. Development 129: 843-851.

Miura GI, Buglino J, Alvarado D, Lemmon MA, Resh MD, Treisman JE. 2006. Palmitoylation of the EGFR ligand Spitz by Rasp increases Spitz activity by restricting its diffusion. Dev Cell 10: 167-176.

Mulligan KA, Fuerer C, Ching W, Fish M, Willert K, Nusse R. 2012. Secreted Wingless-interacting molecule (Swim) promotes long-range signaling by maintaining Wingless solubility. Proc Natl Acad Sci 109: 370-377.

Nakano Y, Kim HR, Kawakami A, Roy S, Schier AF, Ingham PW. 2004. Inactivation of dispatched 1 by the chameleon mutation disrupts Hedgehog signalling in the zebrafish embryo. Dev Biol 269: 381-392.

Ohlig S, Farshi P, Pickhinke U, van den Boom J, Hoing S, Jakuschev S, Hoffmann D, Dreier R, Scholer HR, Dierker $\mathrm{T}$, et al. 2011. Sonic hedgehog shedding results in functional activation of the solubilized protein. Dev Cell 20: 764-774.

Pepinsky RB, Zeng C, Wen D, Rayhorn P, Baker DP, Williams KP, Bixler SA, Ambrose CM, Garber EA, Miatkowski K, et al.
1998. Identification of a palmitic acid-modified form of human Sonic hedgehog. I Biol Chem 273: 14037-14045.

Porter JA, Ekker SC, Park WJ, von Kessler DP, Young KE, Chen CH, Ma Y, Woods AS, Cotter RJ, Koonin EV, et al. 1996a. Hedgehog patterning activity: Role of a lipophilic modification mediated by the carboxy-terminal autoprocessing domain. Cell 86: 21-34.

Porter JA, Young KE, Beachy PA. 1996b. Cholesterol modification of hedgehog signaling proteins in animal development. Science 274: 255-259.

Rietveld A, Neutz S, Simons K, Eaton S. 1999. Association of sterol- and glycosylphosphatidylinositol-linked proteins with Drosophila raft lipid microdomains. I Biol Chem 274: 12049-12054.

Schauerte HE, van Eeden FJ, Fricke C, Odenthal J, Strahle U, Haffter P. 1998. Sonic hedgehog is not required for the induction of medial floor plate cells in the zebrafish. Development 125: 2983-2993.

Strigini M, Cohen SM. 1997. A Hedgehog activity gradient contributes to AP axial patterning of the Drosophila wing. Development 124: 4697-4705.

Taipale J, Chen JK, Cooper MK, Wang B, Mann RK, Milenkovic L, Scott MP, Beachy PA. 2000. Effects of oncogenic mutations in Smoothened and Patched can be reversed by cyclopamine. Nature 406: 1005-1009.

Takada R, Satomi Y, Kurata T, Ueno N, Norioka S, Kondoh H, Takao T, Takada S. 2006. Monounsaturated fatty acid modification of Wnt protein: Its role in Wnt secretion. Dev Cell 11: 791-801.

Teglund S, Toftgard R. 2010. Hedgehog beyond medulloblastoma and basal cell carcinoma. Biochim Biophys Acta 1805: 181-208.

Thisse C, Thisse B. 2008. High-resolution in situ hybridization to whole-mount zebrafish embryos. Nat Protoc 3: 59-69.

Tsai MT, Cheng CJ, Lin YC, Chen CC, Wu AR, Wu MT, Hsu CC, Yang RB. 2009. Isolation and characterization of a secreted, cell-surface glycoprotein SCUBE2 from humans. Biochem J 422: 119-128.

Tu CF, Yan YT, Wu SY, Djoko B, Tsai MT, Cheng CJ, Yang RB. 2008. Domain and functional analysis of a novel plateletendothelial cell surface protein, SCUBE1. I Biol Chem 283: 12478-12488.

van Eeden FJ, Granato M, Schach U, Brand M, Furutani-Seiki M, Haffter P, Hammerschmidt M, Heisenberg CP, Jiang YJ, Kane DA, et al. 1996. Genetic analysis of fin formation in the zebrafish, Danio rerio. Development 123: 255-262.

Varga ZM, Amores A, Lewis KE, Yan YL, Postlethwait JH, Eisen JS, Westerfield M. 2001. Zebrafish smoothened functions in ventral neural tube specification and axon tract formation. Development 128: 3497-3509.

Varjosalo M, Taipale J. 2008. Hedgehog: Functions and mechanisms. Genes \& Dev 22: 2454-2472.

Wang B, Fallon JF, Beachy PA. 2000. Hedgehog-regulated processing of Gli3 produces an anterior/posterior repressor gradient in the developing vertebrate limb. Cell 100: 423434.

Weinberg ES, Allende ML, Kelly CS, Abdelhamid A, Murakami T, Andermann P, Doerre OG, Grunwald DJ, Riggleman B. 1996. Developmental regulation of zebrafish MyoD in wildtype, no tail and spadetail embryos. Development 122: 271280.

Willert K, Brown JD, Danenberg E, Duncan AW, Weissman IL, Reya T, Yates JR III, Nusse R. 2003. Wnt proteins are lipidmodified and can act as stem cell growth factors. Nature 423: 448-452. 
Wilson CW, Chuang PT. 2010. Mechanism and evolution of cytosolic Hedgehog signal transduction. Development 137: 2079-2094.

Woods IG, Talbot WS. 2005. The you gene encodes an EGF-CUB protein essential for Hedgehog signaling in zebrafish. PLOS Biol 3: e66. doi: 10.1371/journal.pbio.0030066.

Wu BT, Su YH, Tsai MT, Wasserman SM, Topper JN, Yang RB. 2004. A novel secreted, cell-surface glycoprotein containing multiple epidermal growth factor-like repeats and one CUB domain is highly expressed in primary osteoblasts and bones. I Biol Chem 279: 37485-37490.

Yang RB, Ng CK, Wasserman SM, Colman SD, Shenoy S, Mehraban F, Komuves LG, Tomlinson JE, Topper JN. 2002. Identification of a novel family of cell-surface proteins expressed in human vascular endothelium. I Biol Chem 277: 46364-46373.

Zeng X, Goetz JA, Suber LM, Scott WJ Jr, Schreiner CM, Robbins DJ. 2001. A freely diffusible form of Sonic hedgehog mediates long-range signalling. Nature 411: 716-720.

Zhu AJ, Scott MP. 2004. Incredible journey: How do developmental signals travel through tissue? Genes \& Dev 18: 29852997. 


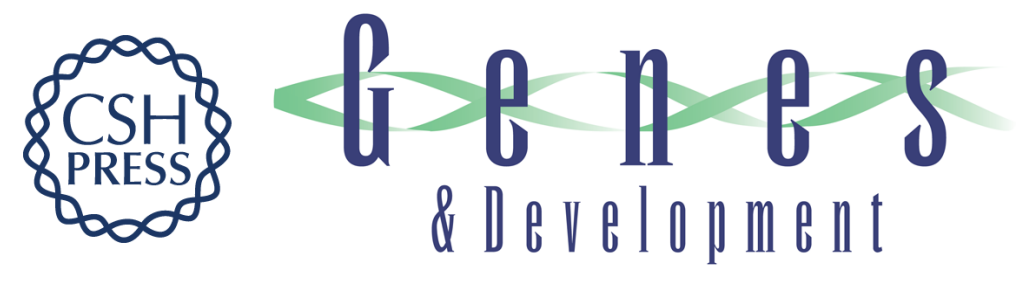

\title{
Scube/You activity mediates release of dually lipid-modified Hedgehog signal in soluble form
}

\author{
Adrian Creanga, Thomas D. Glenn, Randall K. Mann, et al. \\ Genes Dev. 2012, 26: originally published online June 7, 2012 \\ Access the most recent version at doi:10.1101/gad.191866.112
}

\section{Supplemental http://genesdev.cshlp.org/content/suppl/2012/06/11/gad.191866.112.DC1 Material}

Related Content

References

This article cites 54 articles, 26 of which can be accessed free at: http://genesdev.cshlp.org/content/26/12/1312.full.html\#ref-list-1

Articles cited in:

http://genesdev.cshlp.org/content/26/12/1312.full.html\#related-urls

License Freely available online through the Genes \& Development Open Access option.

Email Alerting Receive free email alerts when new articles cite this article - sign up in the box at the top Service right corner of the article or click here.

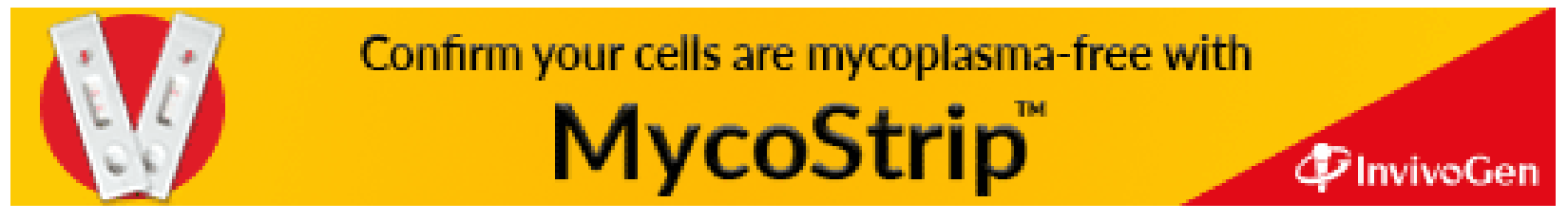

